DOI https://doi.org/10.18551/rjoas.2017-12.38

\title{
DIRECTIONS FOR INCREASING OF AGRO-INDUSTRIAL COMPLEX'S ECONOMIC EFFICIENCY IN THE CONDITIONS OF RUSSIAN FAR EAST MARITIME REGION
}

\author{
Rodionov A.V., Doctor of Economic Sciences \\ Academy of FPS of Russia, Ryazan, Russia \\ Shashlo N.V. ${ }^{*}$, Candidate of Economic Sciences \\ Vladivostok State University of Economics and Service, Vladivostok, Russia \\ *E-mail: ninelllsss@gmail.com
}

\begin{abstract}
The theoretical and practical basis of the effectiveness of the functioning of agro-industrial complex business entities of the Russian Far East maritime region presented in the article. It is proved that the growth of the Russian economy requires the development of agrarian production on an intensive basis, which will ensure food security. The negative consequences of the intensification of agricultural production, based on the maximization of income and the transition to the cultivation of highly profitable monocultures, were revealed.
\end{abstract}

\section{KEY WORDS}

Agribusiness, agro-industrial complex, agrarian sector, plant growing, livestock farming, agro-industrial enterprise, economic efficiency.

In conditions of escalation of food security problems special attention should be paid to the study of the state of agro-industrial production. Estimation of condition of national and regional agro-industrial complex (hereinafter - AIC) is also significant. The level of development of AIC and agro-industrial production is the determining factor not only for food security but also for economic security of the country. Food security issues are usually associated with the provision of country's population with basic food in sufficient quantity and quality, creation of state reserves and reserves of food and agricultural products, as well as the definition of the size of exports and imports. Solution of these questions requires an integrated system of agriculture and the agrarian market management development, implementation of modern tools and incentives to improve the system of food products' quality control. In the context of these tasks, relevant is the study of regional agro-industrial complex's development and functioning as the basis for the functioning of the agro-food market.

In recent years the agricultural sector of Russia has reached a stable positive dynamics, the tendency of agricultural production increasing is observed.

The process of formation of the structure of production and system of its organization are mainly completed as a result of land and agrarian reforms. Further development of agriculture, and plant growing as one of the elements of APICK, requires qualitative transformations, capable to provide competitiveness of production and food security of Russia. Solving of these problems is connected with strategic guidelines for the development of agriculture and plant growing in particular, which will be implemented by state policy in line with regulatory, financial-economic and other regulation of the branch. Key focus of this policy is the need of formation in the Russian Federation the innovative-investment model of development of agriculture, capable to ensure sustained accelerated growth.

\section{MATERIALS AND METHODS OF RESEARCH}

Subject and source base of the study is determined by the objective of the research. The study of AIC development and regulation of agricultural sphere's development problems 
was the subject of numerous works of a number of scientists. Among them were V.G. Andreychuk, A. I. Altukhov, A. G. Babenko, V. M. Bautin, and S. N. Kvasha, V.I. Nechaev, V. V. Reimer, V. G. Tkachenko, P. T. Sabluk, I. G. Ushachev and others [6; 8; 11]. However, the volatility of the economic environment becomes relevant further search of ways of improvement of the efficiency of agricultural production, which determines the actuality of this article.

The purpose of this article is to estimate the status of AIC development, particularly the agricultural sector, as a precondition of food security of Russia and development of priority directions of efficiency of functioning increase of regional agribusiness subjects. The tasks were solved using the following methods of research: method of system analysis, monographic, logical, calculation-structural, graphic and other methods of scientific abstraction and logical generalization.

\section{RESULTS OF STUDY}

The AIC and its basic branch (agriculture), are the major strategic areas of the economy which form the agricultural market, food and economic security, labour and settlement potential of rural areas [1,2]. AIC is an important sector of the national economy, including economic activity in production of agricultural products, food products, logistics (delivery to the final consumer). Functioning of other sectors of the economy significantly depend on the plant growing. Agricultural production occupies a central place in AIC. The growth of the Russian economy requires the development of agricultural production on intensive basis, which will ensure food security of country and guarantee to every person the opportunity of good nutrition with quality and safe products and realize competitive advantages of the country on the world food markets.

Plant growing usually form a substantial part of the national economy's GDP (Pic.1).

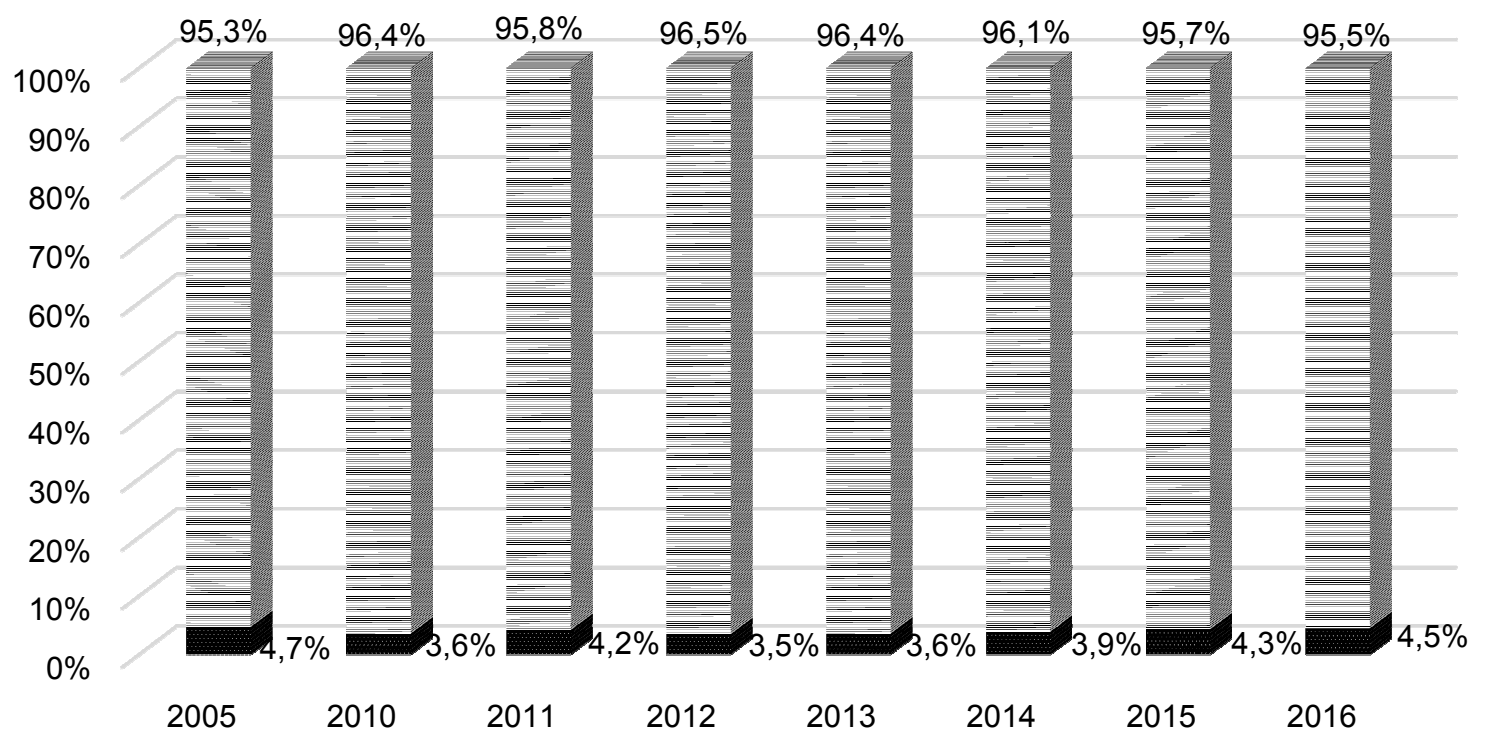

- Gross value added of agriculture (in basic prices)

- Gross value added of other branches of national economy (in basic prices)

Picture 1 - The share of agriculture's gross value added in Russia's GDP,\% [7]

The research of the retrospective and current state of development of agrarian sector of Russian Far East maritime region it should be noted that for the period since 1990, the agricultural sector has experienced transformational changes associated with land reform and establishment of market relations. As a result of reforms, in the role of main business 
entities in the agricultural sector of the region appeared farms, agricultural organizations, agricultural and agro-industrial enterprises.

It should be noted that the territory of Russian Far East maritime region belongs to the territories with extreme natural-climatic conditions for agricultural production. According to the principle agro-climatic zoning - Russian Far East maritime region is the south territory.

Russian Far East maritime region has a fairly developed agriculture. Here enterprises grow rice, soybeans, wheat, barley, oats, potatoes and vegetables. Developed dairy cattle breeding, reindeer breeding and beekeeping. In 2015, agriculture provided the volume of production in the amount of 35.1 billion rubles, which amounted to $0.7 \%$ of the total cost of production of agriculture of the Russian Federation. It was the 46-th place among regions of Russia. The region accounts for a considerable part of Russian production of fish and fish products processed and canned. In 2015, the agricultural production of Russian Far East maritime region per capita at current prices was on the 65th place with 18.2 thousand rubles. The number of people employed in agriculture reached in 20157.8 thousand, while in agricultural production, operated 219 agricultural organizations, 947 farms and 183 thousands of private farms of the citizens. The production of agricultural products by all categories of farms in 2015 amounted to 35.1 billion rubles.

In the conditions of world population rising and the reduction of areas suitable for cultivation of crops, it is very important for each country to make full and effective use of the potential of the earth as one of the competitive advantages of domestic agriculture. Agricultural land use is one of the most important forms of land use. That is agricultural land use has the highest involvement of such a natural resource as the land in economic turnover. No sector of the economy is in such close relationship with the environment as agriculture.

The arable lands of the Far East because of the variety of climate, due to the great length from North to South and from West to East, have different potential fertility (table 1). Basically it is a low natural fertility and suitability of land for agriculture within the zone of influence of the monsoons and risks. The area of agricultural land on 01.01.2016 formed the share of $10 \%$ of the Region. In 2006 this share was $11.6 \%$. More than a half $(55 \%)$ of land of the region is covered by forest.

Table 1 - Area of agricultural land in the Russian Far East maritime region (thousand ha,\%)

\begin{tabular}{|c|c|c|c|c|c|c|c|}
\hline \multirow{2}{*}{ Main crops } & \multicolumn{7}{|c|}{ Area of agricultural land } \\
\hline & 2005 & 2010 & 2011 & 2012 & 2013 & 2014 & 2015 \\
\hline The area of agricultural land, thsd ha & 1651,5 & 1648,6 & 1648,4 & 1648,5 & 1648,5 & 1648,5 & 1649,2 \\
\hline The area of the agricultural land, in $\%$ of the total area & 10,0 & 10,0 & 10,0 & 10,0 & 10,0 & 10,0 & 10,0 \\
\hline $\begin{array}{l}\text { Sown area of agricultural crops in all categories of farms, } \\
\text { thsd ha }\end{array}$ & 340,1 & 314,0 & 340,8 & 379,4 & 379,0 & 423,9 & 413,7 \\
\hline \multicolumn{8}{|l|}{ Including: } \\
\hline - the acreage of grain and leguminous crops & 107,1 & 80,2 & 103,3 & 118,6 & 106,7 & 113,2 & 101,6 \\
\hline - the acreage of technical crops & 137,1 & 139,4 & 146,5 & 171,5 & 176,0 & 218,2 & 223,0 \\
\hline - the areas sown with sunflower & 0,0 & 0,0 & 0,0 & 0,0 & 1,0 & 0,0 & 0,0 \\
\hline - the acreage of potatoes & 30,9 & 31,3 & 32,0 & 32,4 & 30,6 & 30,6 & 29,9 \\
\hline - acreage of vegetables & 8,9 & 10,0 & 10,9 & 10,6 & 10,4 & 9,5 & 9,4 \\
\hline \multicolumn{8}{|c|}{ The structure of sown areas of agricultural crops in farms of all categories, in $\%$ of total arable land: } \\
\hline - grains and legumes & 31,5 & 25,5 & 30,3 & 31,3 & 28,2 & 26,7 & 24,6 \\
\hline - technical culture & 40,3 & 44,4 & 43,0 & 45,2 & 46,4 & 51,5 & 53,9 \\
\hline - potatoes and melons & 11,8 & 13,3 & 12,8 & 11,5 & 11,0 & 9,6 & 9,7 \\
\hline - fodder crops & 16,5 & 16,8 & 13,9 & 12,0 & 14,4 & 12,2 & 11,8 \\
\hline
\end{tabular}

The region is on the 41st place by the size of cultivated areas in Russia - 413,7 thousand of ha $(0.5 \%$ of the total cultivated area of Russia). More than $80 \%$ of arable lands of the Far East are concentrated in the maritime region. First place in the structure of sown areas of Russian Far East maritime region is soy (53.9\% of all space), corn $(8,6 \%)$, rice $(5.0 \%)$, oats $(4.6 \%)$, wheat $(4.4 \%)$.

The region is formed by Khanka-Ussuri, Forest and Coastal areas of specialization of agriculture. Most favorable for the development of agricultural production are the KhankaUssuri area, and the southern subzone of the Coastal zone, giving nearly $85 \%$ of the gross 
output of agriculture in the region. The share of crop production is $52,8 \%$ of the total cost produced in the Russian Far East maritime region agricultural production. The share of livestock is up to $47.2 \%$.

Table 2 - Economic efficiency of agricultural production in Russian Far East maritime region

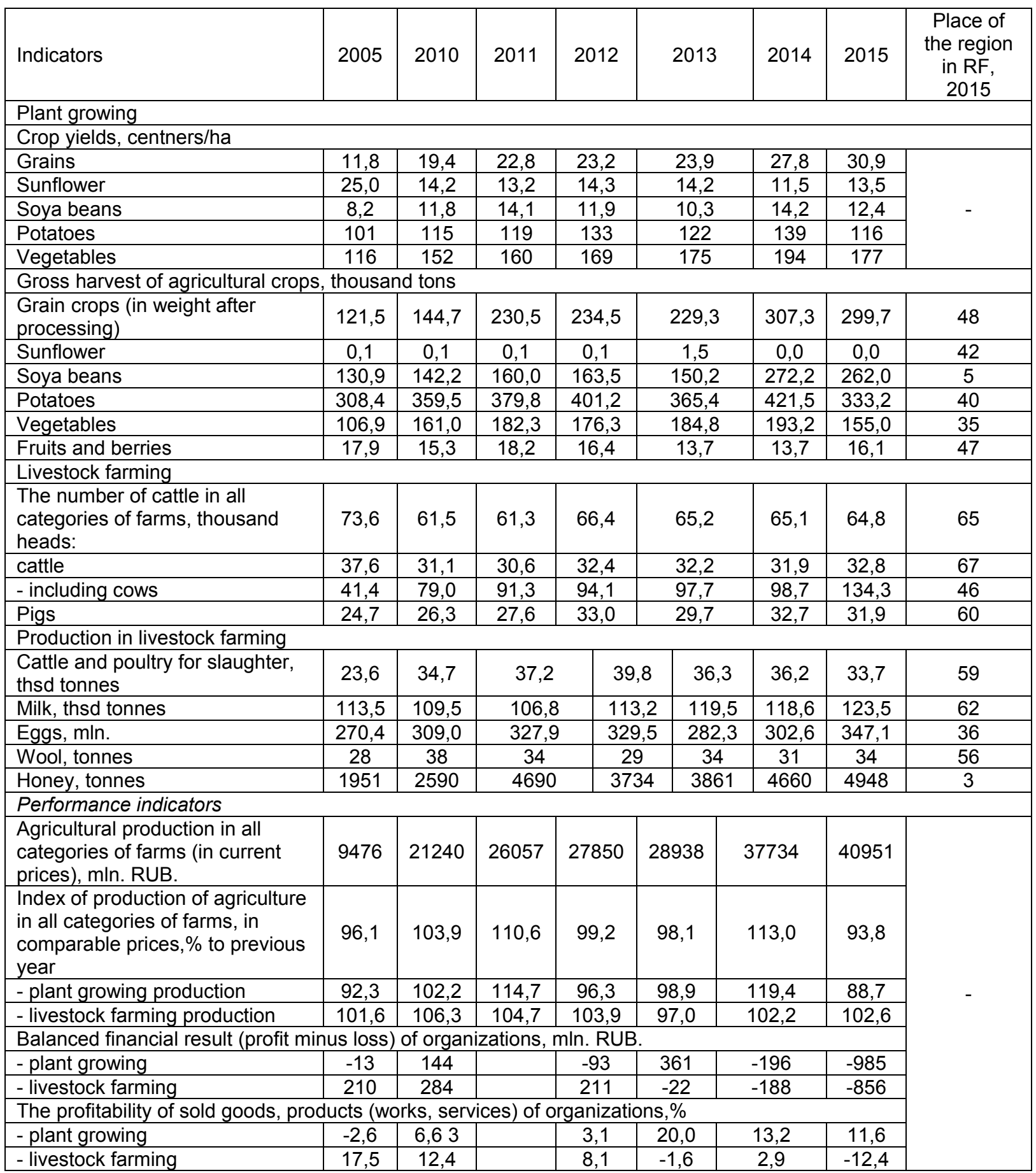

In 2015 Russian Far East maritime region was on the 3rd place in Russia by the indicator of the production of soybeans (262 thousand tons), or $9.7 \%$ of the total fees of this culture by the end of 2015; production of rice was on the 4th place with 50.7 thousand tons or $4.6 \%$ of the national crop of rice; production of beans - 9-th place among regions, or $4.4 \%$ of the total Russian volumes; melon food crops - 12-th place, or $0.8 \%$, field vegetables - 16 -e a place, and $1.0 \%$; corn -16 th place, or $1.4 \%$. 
The analysis shows the transformation of the structure of sown areas for the analyzed period. One of the important legumes soybeans becomes, in 1990 the share of acreage of soybean crops accounted for $21 \%$, in 2015 of $66 \%$. This culture is one of the most costeffective - the level of profitability of production in the Russian regions ranges from $5 \%$ to $50 \%$. At the same time, it is necessary to ensure the preservation of fertility of agricultural lands and their normal phytosanitary condition, in this case, the growth of the area under soybean must be accompanied by the expansion of cultivation of perennial grasses and grain crops.

Livestock farming Russian Far East maritime region is presented by main streams: milk and meat cattle breeding, pig breeding, industrial poultry keeping. Small businesses units are engaged in rabbit breeding and breeding of small cattle (goats and sheep). Product of the livestock branch of agriculture in the region in 2015 placed on following position: pork production - 54-th place among regions of the Russian Federation, beef - 65-th place, poultry - 44-th place, lamb and goat meat - 65-th place, milk - 62-nd place, eggs - 36-th place.

In a market economy where all factors of the production process must not only be formed in optimum proportions, but used to maximum effect, not so important to have a certain resource, how to use it effectively. Under the cost-effective use of land scientists understand land use, economic viability which is determined by the ratio of economic effect with the area of the land plot in accordance with its quality and distance. Economic efficiency of use of agricultural land in Russian Far East maritime region, reflected in the economic efficiency of agricultural production, is characterized by positive dynamics (table 2): there is an increase in gross charges of production and crop yields.

By the results of the conducted analysis it can be noted that the gross output of agriculture in Russian Far East maritime region during the last five years has increased by $10-20 \%$. The major share of the crop formed potatoes and vegetables, grains, livestock farming of cattle, pigs and poultry, production of milk, honey and eggs. In the Far East of Russia, the priorities recognized by the industry of soya cultivation, rice, and grains production. In 2015 in all categories of farms, milk production reached the level of $105 \%$, compared with the level of 2014. Index of production in agricultural organizations, in comparison with 2014 , was $116 \%$. Compared to 2011 , milk production in five years increased by $16 \%$. Production growth was gained due to the increase in the number of dairy cows in farms of all categories. Their number increased to $102 \%$ in relation to 2014 . In agricultural organizations the number of cows raised on 3.5\% compared to 2014 .

Also tend to increase natural indicators - crop yields. However, the growth of gross output may occur with a reduction in gross yield, or constant level at the expense of price growth [10].

Land resources are the basis of production and economic activity in agriculture. Their effective use in modern conditions should be based on such principles as the equality of all forms of ownership of land, payment for land-use, targeted, rational and environmentally safe use of land. But the intensification of agricultural production based on maximizing income and transition to highly profitable cultivation of monocultures leads to negative consequences, such as: contamination of land by residues of chemicals as a result of their constant and uniform usage; lower prices for agricultural products as a result of proposals growth; loss of traditional markets for other agricultural products; the failure of rational types of rotations; selling raw materials and not products with high added value; ignoring the principle of comlex agricultural production and the decline of beef and dairy cattle; increased degradation of agricultural lands; the destructive influence of agrolandscape and biodiversity.

Features of agricultural production of the transition period and market economy are the following: sharp decline in gross agricultural production (1990-2000) turned gradual increase since 2000, due to the formation of the diversity in rural areas and the creation of organizational and legal structures of the market type; created new agricultural enterprises of market type, various organizational-legal forms of business activity which becomes profitable; ability to implement entrepreneurial skills have helped raise the level of productivity in agricultural production; overcome the negative trend of loss of livestock 
production, the trend of increasing profitability; the growth of profitability of agricultural enterprises helped to increase average monthly wages in agriculture.

The result of the study revealed the problems of plant industry of Russian Far East maritime region, which are the following: expansion of acreage under cultivation of cultures than cause depletion of the soil; reduced crops fodder crops group, cereal crops, legumes; low crop yields, increase which is feasible through the use of modern and innovative resource-saving technologies; the concentration of production of fruit and vegetables in households that do not have appropriate storage facilities to store it; the lack of infrastructure implementation of such products through a fruit and vegetable store; high energy - and resource-intensive crop production; lack of innovative approaches for the treatment of soil and crops cultivation system (No-Till, organic production, drip irrigation); deficit of highly qualified personnel who are able to work on the latest tools and perform high-tech operations to grow crops; lack of financial resources for building productive capacities, the acquisition of machinery and equipment.

The main problems of the livestock industry are: reduction of a livestock of cattle, cows; the inability of small farms to produce products that meet international quality standards; the total decline in production of livestock products; import of food products of animal origin with low quality; absence in the region of domestic breeding base of highly productive breeds of cattle and pigs; decrease in the production of high quality beef and pork, and replacing it with cheaper and less energetically valuable poultry, mainly chicken intensive cultivation technology.

\section{CONCLUSION}

The results of the study indicate that Russian Far East maritime region, as well as the country as a whole, does not provide food security in full. Agriculture of the region is influenced by many factors such as: availability of water and land resources, unfavorable climate for the cultivation of many crops, food imports. In our opinion, to ensure food security, taking into account all risks, directions of agricultural policy should be the following: improving soil fertility and productivity, the expansion of sowing of crops at the expense of unused land, reconstruction and building of meliorative systems; the expansion and use of potential marine biological resources; the creation of new technologies of complex processing of food raw materials, methods of storage and transportation; improved utilization of scientific and technical potential; development of scientific potential of AIC, the implementation of measures to prevent the outflow of scientific personnel; development of system of training, capable to solve tasks of development of the agricultural sector with the requirements of food security; increased rate of structural modernization of the agricultural sector, reproduction of natural ecological potential; improvement of mechanisms of regulation of agricultural market and elimination of price disparity; formation of the pricing mechanism on the basis of indicative prices for key products; increase availability of food to all population groups; formation of a healthy type of food through the development of programs on problems of healthy nutrition; accelerated development of the infrastructure of the agro-food market; improving the system of food safety monitoring: monitoring of compliance with the requirements of the legislation in the field of agricultural products and foodstuffs, including those imported; to monitor the distribution of food products derived from genetically modified plants using genetically modified microorganisms.

Thus, we can conclude that the primary task of macroeconomic regulation is dramatically changing business environment. The solution to this problem, in our view, requires: strengthen the regulatory role of the state, which will reduce the stochasticity of the conditions of functioning of agricultural enterprises; development and implementation of strategic management principles; development of state scientific and technical and economic programs in priority directions of development of the agrarian economy; development and implementation of new approaches to the taxation system based on strengthening the role of stimulating function of taxes; implementation of new financial policies aimed on stimulating demand and investment activity while containing inflation; the formation of a favorable 
investment climate through tax benefits, including benefits on the territories of accelerated development, and increased capital investment as an instrument of state agricultural policy; improvement of market mechanisms of price regulation, including price parity relations for all types of products; improving the competitiveness of agricultural enterprises; preferential crediting of agricultural enterprises; development of new resource-saving technologies of production; introduction of modern methods of management of enterprises; the formation of specialized areas and concentration of production of agricultural products and foodstuffs, vertically integrated structures.

The implementation of these priority measures is almost independent from business entities and is a long process. Therefore, at the present time significantly increases the value of the transformation of the internal environment of agricultural enterprises to ensure their competitiveness. Improving efficiency in the agricultural economy requires the development of agricultural production on intensive basis, which will ensure food security of the country, guaranteeing to every person the possibility of full nutrition and quality safe food products and to realize the competitive advantages of countries on world food markets.

\section{REFERENCES}

1. State program of development of agriculture and regulation of markets of agricultural products, raw materials and food for 2013 - 2020 years. Approved by the Russian Federation Government decree from July 14, 2012 №717 // access Mode: http://government.ru/programs/208/events/

2. State program of Maritime region "Development of agriculture and regulation of markets of agricultural products, raw materials and food. Raising the standard of living of the rural population of the Maritime region" for 2013 - 2020 years, approved by the resolution of the Maritime region Administration from 07.12.2012 № 392-PA// access Mode: http://docs.cntd.ru/document/494222351

3. Maritime region in the figures. 2014: Short statistical book/ Primorskstat, 2015. - 89 p.

4. The Regions of Russia. Main characteristics of subjects of the Russian Federation. 2016: Stat. coll. M.: Rosstat., 2016. 671 p.

5. The Regions of Russia. Socio-economic indicators. 2016. M.: Rosstat., 2016. 1326 p.

6. Rejmer V. V. Innovation-oriented development of agriculture in the Russian Far East: monograph / V. V. Reimer, A. V., Ulezko, A. A. Tutunikov. - Voronezh: Voronezh SAU, 2016. -347 p.

7. Russia in figures. 2017. Short stat. data. M.: Rosstat., 2017. 511 p.

8. Fishing industry of the Far East of Russia : current state, problems and prospects of competitiveness : monograph / O. Y. Vorozhbit. - Vladivostok: VGUES, 2016. - $156 \mathrm{p}$.

9. Agriculture, hunting and hunting economy, forestry in Russia. 2015. Stat. coll. M.: Rosstat., 2015.. - 201 p.

10. The efficiency of agricultural production (guidelines) / ed. by I.S. Sandu. - M.: "Rosinformagrotech", 2013. - $228 \mathrm{p}$.

11. The impact of property development on the increase of efficiency of agrarian enterprises in the conditions of activity of the Ukrainian regions: monograph / V.G. Tkachenko. Kiev: Publishing house, 2013. - 224 p. 